\title{
Octávio de Freitas, de titular a patrono*
}

\author{
Octávio de Freitas, from incumbente to patron
}

\author{
Luiz de Gonzaga Braga Barreto ${ }^{1}$ \\ ${ }^{1}$ Médico, Membro do Instituto Pernambucano de História da Medicina. \\ e-mail: lgbarreto@uol.com.br
}

O Prof. Octávio de Freitas fundou juntamente com outros médicos do Recife, em 26 de agosto de 1946, o Instituto Pernambucano de História da Medicina por influência e incentivo do Dr. Ivolino de Vasconcelos, do Rio de Janeiro.

O Instituto foi criado em reunião convocada pelo Prof. Octávio de Freitas e realizada em sua residência à Rua Dom Bosco, no 779 no Recife. A essa reunião acorreram além do interessado, Leduar de Assis Rocha, Durval Lucena, Francisco Montenegro, Joaquim Cavalcanti, Armando Maia, Pierre Rouquayrol, Albérico Câmara, Lucilo Maia, Abreu e Lima, Vanderley Brada, Osvaldo Lima e Galvão Raposo.

O Instituto ficou composto com a participação de 18 médicos, 3 dentistas, 3 farmacêuticos, 3 químicos e 3 veterinários.

$\mathrm{Na}$ mesma reunião foi aclamada a sua diretoria constituída das seguintes personalidades: presidente, Prof. Octávio de Freitas; vice-presidente, farmacêutico, Pierre Rouquayrol; $1^{\circ}$ secretário, Dr. Leduar de Assis Rocha; $2^{\circ}$ secretário, Dr. Francisco Montenegro; tesoureiro, Prof. Galvão Raposo.

Criada a instituição quis o seu presidente the dar uma ampla divulgação e promoveu uma sessão solene para a sua instalação que foi realizada na Sociedade de Medicina de Pernambuco, em um domino, 17 de novembro de 1946, às 20 horas. Uma significativa data escolhida pelo Dr. Octávio de Freitas, quando há 100 anos passados, era mandado fundar o Hospital de Pedro II pela Lei Provincial de $\mathrm{n}^{\circ} 165$, de 17 de novembro de 1846.

Para esse evento foram convidadas além da classe médica, outras autoridades, inclusive o interventor federal no Estado, àquele tempo, o General Demerval Peixoto, convidado pessoalmente pelo Dr. Octávio de Freitas em audiências especial marcado *Palestra proferida no Instituto Pernambucano de Pernambuco, Recife, no dia 8 de dezembro de 2018. no palácio do governo. Na data, não podendo ele comparecer a solenidade foi representado pelo secretário de Saúde e de Educação, Prof. Luiz Delgado, que presidiu a solenidade.

No seu discurso o Prof. Octávio de Freitas fez uma ampla dissertação sobre os objetivos e os motivos para a criação do Instituto Pernambucano de História da Medicina, instituição que está filiada ao Instituto Brasileiro de História da Medicina, com sede no Rio de Janeiro, e que foi criado pelo Dr. Ivolino de Vasconcelos, em 20 de novembro de 1945, e que era também o seu presidente.

Octávio de Freitas falou também da importância das práticas médicas desenvolvidas no estado de Pernambuco e que o seu registro não estava sendo realizado pelos escritores médicos do sul do país, que tinham a primazia de se envolver na descrição desses eventos, "muito embora tenha sido nesta cidade (do Recife), onde primeiro se cuidou do estudo concernente à ciência e a arte de curar". Citou autores como J. Sampaio Ferraz que tendo escrito um trabalho sobre a "Meteorologia Brasileira" sequer citou os trabalhos realizados em Pernambuco. Com relação àLeonídio Ribeiroque por solicitação da Comissão dos Centenários de Portugal escreveu um livro sobre a Medicina no Brasil, mas igualmente não retratou qualquer assunto sobre as práticas médicas e as instituições de saúde em Pernambuco e em todo o norte do Brasil. Assim, Pernambuco continuava como uma terra desprovida inteiramente de fatos referentes à medicina, citando na oportunidade importantes instituições e iniciativas realizadas no Estado e que não foram contempladas pelo escritor. Assim, a criação do Instituto Pernambucano de História da Medicina poderia proporcionar a recuperação e restauração da história da medicina no estado.

História da Medicina, Memorial da Medicina de 
$\mathrm{Na}$ sua fala ainda acrescenta o Prof. Octávio de Freitas sobre a organização da instituição, que para cada um dos associados titulares foi escolhido um patrono, todos profissionais de reconhecida capacidade científica, profissional e ética. E que os associados estavam com a responsabilidade de resgatar e contar os feitos gloriosos de cada um dos patronos relacionados à sua formação, as suas pesquisas e atividades profissionais.

Após essa cuidadosa e esclarecedora narrativa ele convocou o Dr. Albérico Câmara para apresentar o seu trabalho sobre o Hospital Pedro II que estava completando, por aquela época, o seu primeiro centenário.

Cabe a mim ainda, para fazer jus o título deste artigo, salientar que após o falecimento do Dr. Octávio de Freitas, em 26 de janeiro de 1949, na reunião convocada pelo Dr. Leduar de Assis Rocha e realizada em 22 de março de 1949, ele foi eleito como presidente do Instituto Pernambucano de História da Medicina em substituição ao falecido. A sua eleição foi notificada em periódicos do Recife e também em alguns do Rio de Janeiro, cidade em que funcionava a sede do Instituto Brasileiro de História da Medicina, dirigido pelo Dr. Ivolino de Vasconcelos.

E ainda, o mais importante, o presidente Dr. Leduar de Assis Rocha convocou uma reunião que se realizou no dia 2 de junho de 1949, e na oportunidade, com a aprovação de todos os presentes, foi criada uma nova cadeira no Instituto Pernambucano de História da Medicina, a de número 31, sendo designado como seu patrono o Prof. Octávio de Freitas. Uma merecida homenagem. 